\title{
O controle social no Sistema Único de Saúde: um olhar crítico à Resolução $n^{\circ} 453 / 2012$
}

The social control in the Unified Health System: a critical eye at Resolution $n^{\circ} 453 / 2012$

RESUMO O ensaio reflete sobre a Resolução $n^{0} 453 / 12$, do Ministério da Saúde e do Conselho Nacional de Saúde, que aprovaram diretrizes instituindo, reformulando e reestruturando o funcionamento dos Conselhos de Saúde para o enfrentamento de sua legitimação institucional e estruturação, para que a sociedade sinta a presença permanente da possibilidade de se envolver nos assuntos de saúde pública, sem custos pessoais ou financeiros, sem demoras e sem timidez. São discutidos criticamente pontos capazes de potencializar conflitos de entendimento das normas e dos prejuízos à autonomia e à garantia da abrangência do controle social nas políticas públicas de saúde.

PALAVRAS-CHAVE Conselhos de Saúde. Sistema Único de Saúde. Saúde pública.

ABSTRACT The essay reflects on the Resolution $n^{\circ} 453 / 12$ of the Ministry of Health and the National Health Council, which approved guidelines by instituting, reformulating and restructuring the functioning of Health Councils in facing their institutional legitimation and structuring, so that society feels the presence of the possibility of engaging in public health matters, without personal or financial costs, without delay and without timidity. Critical points are discussed that are capable of potentiate conflicts of understanding of the norms and impairments to the autonomy and the guarantee of the comprehensiveness of the social control in the public health policies.

KEYWORDS Health Councils. Unified Health System. Public health.

1 Universidade Estadual do Oeste do Paraná (Unioeste) - Marechal Cândido Rondon (PR), Brasil.

dartelferrari07@gmail.com

2 Irmandade da Santa

Casa de São Paulo,

Departamento de

Ortopedia e Traumatologia

- São Paulo (SP), Brasil.

lohranangueralima@gmail.

com 


\section{Introdução}

O presente ensaio versa sobre a análise crítica da Resolução $n^{\circ} 453$, de 10 de maio de 2012, do Ministério da Saúde e do Conselho Nacional de Saúde. O ato objetiva a normatização e a aprovação de diretrizes para instituição, reformulação, reestruturação e funcionamento dos Conselhos de Saúde e revoga as disposições em contrário, na premissa de que o fortalecimento da participação da comunidade na gestão das políticas de saúde pública deve oportunizar a inserção ativa dos sujeitos no contexto de atenção e promoção da saúde potencializada por decisões políticas institucionais.

O objetivo principal da Resolução no 453 é consolidar, fortalecer, ampliar e acelerar o processo de controle social do Sistema Único de Saúde (SUS) brasileiro, por intermédio dos Conselhos Nacional, Estaduais, Municipais, das Conferências de Saúde e Plenárias de Conselhos de Saúde, conforme o $95^{\circ}$, inciso II, do art. $1^{\circ}$ da Lei ${ }^{\circ} 8.142$, de 28 de dezembro de 1990, que dispõe sobre a participação da comunidade na gestão do SUS e outorga ao Ministério da Saúde, mediante portaria do Ministro de Estado, autoridade para estabelecer a regulamentação dos dispositivos legais propostos.

Este trabalho procurou confrontar criticamente os pontos de avanço e os pontos nebulosos das normas contidas na atual Resolução. Essa análise se limitou à interpretação plausível a ser dada aos princípios e às diretrizes da norma para a sua aplicação prática no cotidiano de um Conselho de Saúde. Tal enfoque se faz necessário para verificar a adequabilidade da Resolução à ordem funcional dos Conselhos de Saúde, considerando a necessidade de aprimoramento do controle social da saúde no âmbito nacional, e às reiteradas solicitações dos Conselhos Estaduais e Municipais referentes à normatização de composição, organização e funcionamento de seus colegiados.

\section{O controle social no SUS e o objeto de estudo}

A atenção à saúde como um direito universal e gratuito foi firmada na Constituição de 1988, nos artigos 196 a 200. Segundo expresso no artigo 198, as ações e os serviços públicos de saúde que integram a rede regionalizada e hierarquizada constituem um sistema único, que deverá ser organizado de acordo com diretrizes estruturadas na descentralização, com direção única em cada esfera de governo, no atendimento integral, com prioridade para as atividades preventivas, sem prejuízo dos serviços assistenciais, e, finalmente, na participação da comunidade (BRASIL, 1988).

A efetiva participação da sociedade civil organizada nas decisões de gestão do Sistema Público de Saúde passou por processos de amadurecimento ao longo dos anos, resultando em um sistema de controle social mais qualificado, deliberativo, independente e representativo. Dois anos depois da Promulgação da Constituição, duas leis trouxeram conteúdos importantes sobre essa atuação. Trata-se das Leis: $n^{\circ}$ 8.080/90, conhecida como Lei Orgânica da Saúde, que dispõe sobre as condições para a promoção, a proteção e a recuperação da saúde, a organização e o funcionamento dos serviços correspondentes; e da Lei $n^{\circ}$ 8.142/90, que dispõe sobre a participação da comunidade na gestão do SUS (BRASIL, 2013).

A partir de então, a atuação da comunidade no sistema de saúde foi ampliada, democratizada, regulamentada e passou a ser denominada 'controle social'. Em seu processo de consolidação no âmbito das políticas públicas, a população, por meio dos Conselhos e das Conferências de Saúde, passa a exercer o controle social, participando do planejamento e da fiscalização das ações governamentais no âmbito da saúde, estabelecendo relações que contemplam a diferença de interesses dos segmentos de usuários, gestores, prestadores de serviço e 
trabalhadores de saúde em todas as esferas de governo.

O Plenário do Conselho Nacional de Saúde, em sua Ducentésima Trigésima Terceira Reunião Ordinária, realizada nos dias 9 e 10 de maio de 2012, no uso de suas competências regimentais e atribuições conferidas por Lei, aprova a Resolução $n^{0} 453$, que estabelece diretrizes para instituição, reformulação, reestruturação e funcionamento dos Conselhos de Saúde e revoga a Resolução no 333/2003 (BRASIL, 2012). O objetivo principal da proposta de reformulação das diretrizes é dar mais clareza às normas orientadoras de estruturação e funcionamento dos Conselhos de Saúde. No entanto, percebem-se algumas 'falhas e lacunas' merecedoras de um foco de análise específico, primeiro, apontando-as, e, posteriormente, propondo modificações.

Portanto, este estudo se dedicou a analisar criticamente a Resolução $n^{\circ} 453$, de 2012, no anseio de ampliar a discussão das diretrizes orientadoras da estruturação e do funcionamento dos Conselhos de Saúde, no sentido de propiciar oportunidades para que a comunidade sinta permanentemente a possibilidade de se envolver nos assuntos do governo referentes à saúde, mediante a efetivação do controle social nas políticas e ações da saúde pública.

\section{A Resolução no 453/2012 em análise}

Inicialmente, no preâmbulo da Resolução $n^{0} 453 / 2012$, observa-se a preocupação com a revisão linguística no sentido de ampliar a legibilidade do texto segundo a função tratada por ele. No texto revogado, especificamente em sua descrição de aprovação do conteúdo, haviam utilizado o termo 'criação' dos Conselhos de Saúde com referência à formação desse colegiado. Agora, na resolução atual, de modo mais apropriado, a ação denominada 'criação' foi cambiada para 'instituição'. A palavra 'criar' tem origem etimológica no Latim creare, 'produzir, erguer' e está relacionada à ação crescere, 'crescer, aumentar'. A palavra 'instituição' tem origem no Latim institutio, cujo sentido geral, desde meados do século XIX, reporta à 'organização de sociedades', que, segundo Firth e Raymond (2010), consiste na ordenação sistemática de relações sociais pelos atos da escolha e da decisão, segundo a qual os indivíduos baseiam suas ações nas normas da estrutura social na qual convivem. O texto aprovado passa a ter a seguinte redação: "aprovar as seguintes diretrizes para 'instituição' [grifo nosso], reformulação, reestruturação e funcionamento dos Conselhos de Saúde" (BRASIL, 2012, N. P.).

A Primeira Diretriz da Resolução $n^{\circ}$ $453 / 2012$, por seu turno, define o termo 'Conselho de Saúde' como:

O Conselho de Saúde é uma instância colegiada, deliberativa e permanente do Sistema Único de Saúde (SUS) em cada esfera de Governo, integrante da estrutura organizacional do $\mathrm{Mi}$ nistério da Saúde, da Secretaria de Saúde dos Estados, do Distrito Federal e dos Municípios, com composição, organização e competência fixadas na Lei no 8.142/90. O processo bem-sucedido de descentralização da saúde promoveu o surgimento de Conselhos Regionais, Conselhos Locais, Conselhos Distritais de Saúde, incluindo os Conselhos dos Distritos Sanitários Especiais Indígenas, sob a coordenação dos Conselhos de Saúde da esfera correspondente. Assim, os Conselhos de Saúde são espaços instituídos de participação da comunidade nas políticas públicas e na administração da saúde. (BRASIL, 2012, N. P.).

Apesar de o renovador remeter a definição de 'Conselho de Saúde' à competência conceitual fixada pela Lei $n^{0} 8.142 / 90$, ele pecou em não explicitar a autonomia desse colegiado. A palavra 'autonomia', de origem grega, formada pelas palavras autos, "por si mesmo', e nomos, 'compartilhar, dar-se nas 
suas próprias leis', significa a capacidade de uma pessoa ou um grupo de pessoas de ser capaz de se autogovernar, de se orientar e agir de forma independente (SPEAR; KULBOK, 2004). A autonomia é um conceito relacional que fundamenta a propriedade constitutiva de independência dos Conselhos de Saúde, na medida em que escolhem as suas normas e os seus valores na tomada de decisões e que agem em consequência dessas escolhas (SIQUeIRA-BATISTA; SCHRANM, 2008). Por esse motivo, a autonomia dos Conselhos de Saúde, presente como sinônimo de independência, deveria estar explícita no texto e de modo destacado.

A Terceira Diretriz da Resolução $n^{\circ}$ 453/2012 trata da organização dos Conselhos de Saúde com foco na disposição de sua composição. Mantém a estrutura quadripartite composta por representantes de entidades, instituições e movimentos representativos de usuários, de entidades representativas de trabalhadores da área da saúde, do governo e de entidades representativas de prestadores de serviços de saúde, estabelecendo o princípio da representação paritária. Aqui, há problemas graves que devem ser apontados. A composição dos Conselhos de Saúde proposta pelos reformadores preserva o ideal de oportunizar a participação dos vários e diferentes segmentos da comunidade no controle social, por isso, mantém a determinação de que os Conselhos de Saúde devem ser compostos por $50 \%$ de entidades e movimentos representativos de usuários, $25 \%$ de entidades representativas dos trabalhadores da área de saúde e $25 \%$ de representação de governo e prestadores de serviços privados conveniados ao SUS ou sem fins lucrativos.

De modo inusitado, gestores e prestadores de serviço foram acomodados em uma mesma categoria e dividem a parcela de vagas sem qualquer justificativa para esse agrupamento. Um lado não pode se confundir com o outro. Se o gestor tem a finalidade administrativa, e o prestador de serviços de execução de serviços, em algum momento, esses dois segmentos podem defender entendimentos divergentes de interesses, descaracterizando similitudes de interesses. Por isso, seria razoável afirmar que a função de prestador de serviços se distingue da função de governo (CARVALHO, 1998). O problema se acumula ao analisar sobre o critério de divisão das vagas entre gestores e prestadores de serviços. Está definido que esses dois segmentos vão compartilhar os $25 \%$ das vagas disponíveis. Resta a presunção de uma divisão igualitária, onde caberiam a cada segmento $12,5 \%$ das vagas. Pelo princípio raso da lógica, tal divisão só seria possível em colegiados constituídos por pelo menos 96 representantes. No entanto, esse número elevado de representantes tenderia a intrincar o funcionamento dos conselhos. Para preservar o princípio da representação proporcional, seria oportuno e adequado providenciar a separação desses dois segmentos para garantir de fato a abrangência e a complementaridade do conjunto da sociedade na representação colegiada.

Não menos importante na Terceira Diretriz é o destaque dado à relação de órgãos e entidades, descrita com potencialidade de representação nos Conselhos de Saúde. Para uma melhor análise da proposta, considera-se de bom alvitre a transcrição da matéria em sua íntegra:
A participação de órgãos, entidades e movi- mentos sociais terá como critério a represen- tatividade, a abrangência e a complementa- ridade do conjunto da sociedade, no âmbito de atuação do Conselho de Saúde. De acordo com as especificidades locais, aplicando o princípio da paridade, serão contempladas, dentre outras, as seguintes representações:
a) associações de pessoas com patologias;
b) associações de pessoas com deficiências;
c) entidades indígenas; 
d) movimentos sociais e populares, organizados (movimento negro, LGBT...);

e) movimentos organizados de mulheres, em saúde;

f) entidades de aposentados e pensionistas;

g) entidades congregadas de sindicatos, centrais sindicais, confederações e federações de trabalhadores urbanos e rurais;

h) entidades de defesa do consumidor;

i) organizações de moradores;

j) entidades ambientalistas;

k) organizações religiosas;

I) trabalhadores da área de saúde: associações, confederações, conselhos de profissões regulamentadas, federações e sindicatos, obedecendo as instâncias federativas;

m) comunidade científica;

n) entidades públicas, de hospitais universitários e hospitais campo de estágio, de pesquisa e desenvolvimento;

o) entidades patronais;

p) entidades dos prestadores de serviço de saúde; e

q) governo. (BRASIL, 2012, N. P.).

Como pode ser visto no texto acima transcrito, a relação desperta especial atenção à representatividade descrita no item (k) ao se referir às organizações religiosas. O destaque apresentado para essa representação se justifica pelo princípio da laicidade do Estado brasileiro. Tal aspecto é o mais importante a ser aduzido desta análise. Inicialmente, é importante estabelecer que a organização religiosa é uma pessoa jurídica de direito privado constituída por pessoas físicas que professam uma religião, portanto, é equivocada a interpretação de que somente as igrejas se classificam como organização religiosa (WEINGARTNER, 2007). A laicidade do Estado brasileiro, determinada pela Constituição Federal de 1988, é a base ideológica do regime da liberdade de expressão religiosa no País, não podendo ser dada preferência a determinada confissão religiosa, oferecendo-se algum benefício que não seja estendido às demais (PIRES, 2015). Atualmente, ainda pairam dúvidas sobre o real entendimento de laicismo do Estado brasileiro. Isso se dá devido às forças social, moral e até mesmo política que a religião predominante representa na sociedade, que, por sua vez, não pode ser suficiente para beneficiar uma determinada organização em detrimento de outra (MONELLO, 2015).

Ainda, o item ' $d$ ' dessa diretriz assegura a participação de movimentos sociais e populares organizados, citando o movimento negro e o LGBT (acrônimo de Lésbicas, Gays, Bissexuais, Travestis, Transexuais e Transgêneros) como exemplos de representatividade para essa categoria. Muito embora os movimentos citados atendam aos quesitos de elegibilidade propostos pela diretriz, o fato de o reformador ter nominado as entidades pode deixar implícita uma orientação de valorização de determinados grupos sobre outros, o que não é aceitável na forma da lei. Não é observada no texto qualquer restrição a qualquer outro movimento social e popular, no entanto, a ausência de exemplificações se apresentaria mais adequada e mais positiva para o entendimento do não privilégio.

Ainda sobre a organização dos Conselhos de Saúde, a Resolução, nos termos do item ' $V$ ', versa sobre a renovação parcial das entidades colegiadas, como segue o texto na íntegra:

V - Recomenda-se que, a cada eleição, os 
segmentos de representações de usuários, trabalhadores e prestadores de serviços, ao seu critério, promovam a renovação de, no mínimo, 30\% de suas entidades representativas. (BRASIL, 2012, N. P.).

Em vista do dispositivo citado, estranhamente, percebe-se o afastamento do segmento de representantes do governo como agente promotor da renovação das entidades representativas. Na tentativa de entender esse afastamento, poderia-se pressupor a lógica de que o segmento de governo será sempre governo. Embora a argumentação pareça razoável, no funcionamento cotidiano dos Conselhos de Saúde, esse entendimento pode ser visto por mais de uma perspectiva. Muito embora governo seja sempre governo, ele também pode e deveria contribuir para a oxigenação dos conselhos, promovendo a renovação dentro do seu próprio segmento e ofertando oportunidades aos diferentes setores da saúde pública de contribuir para o controle social da saúde.

Por fim, o valor mínimo de renovação das entidades sugerido pela norma é de $30 \%$ e representa um corte baseado em impressões puramente empíricas. Não se conhece qualquer estudo representativo e bem controlado que demonstre desfecho positivo no funcionamento e na organização dos conselhos de saúde associado a esse percentual de renovação, muito menos sobre impactos negativos causados pela não renovação. Faz-se necessária aqui a implementação de estudos bem controlados para conhecer tal dinâmica, onde se ponderem as diversidades regionais, estaduais e municipais dos conselhos e de seus conselheiros, a fim de estabelecer parâmetros confiáveis de renovação. Não menos importante é estabelecer garantias de recursos humanos e financeiros para a capacitação continuada dos conselheiros neófitos, sem prejuízo aos demais.

A relevância pública da função do Conselheiro de Saúde está explicitada no item X da Terceira Diretriz, conforme segue:
As funções, como membro do Conselho de Saúde, não serão remuneradas, considerando-se o seu exercício de relevância pública e, portanto, garante a dispensa do trabalho sem prejuízo para o conselheiro. Para fins de justificativa junto aos órgãos, entidades competentes e instituições, o Conselho de Saúde emitirá declaração de participação de seus membros durante o período das reuniões, representações, capacitações e outras atividades específicas. (BRASIL, 2012, N. P.).

Para o bom cumprimento da garantia do não prejuízo trabalhista ao conselheiro em atividade oficial, esse direito necessita ficar mais explícito nas formalidades legais. Os conselheiros submetidos ao artigo $n^{\circ} 473$ da Consolidação das Leis do Trabalho (CLT), que regulamenta o trabalho com carteira assinada no Brasil, frequentemente têm essa garantia não observada. Muitas vezes, em prejuízo do trabalhador, a solicitação de abono de falta é confrontada com a CLT, que define as situações onde as faltas ao serviço estão protegidas de gerar desconto de salário ou de serem compensadas em outros dias de trabalho (motivos como óbito de familiares e dependentes; casamento; nascimento de filho; doação voluntária de sangue; alistamento eleitoral; provas de vestibular; e exigências do serviço militar, da justiça e da representação sindical). Outro problema verificado na redação acima é a ausência de garantia de dispensa das obrigações escolares sem prejuízo ao conselheiro estudante quando no exercício de suas atividades como conselheiro. O direito ao abono de faltas e ao deferimento para recuperar perdas de provas e exames deve ficar explicitamente garantido nas normas.

A Quarta Diretriz da Resolução $n^{\circ}$ $453 / 2012$, no item VIII, trata sobre a necessidade de quórum deliberatório e dicisório e corrige de modo oportuno o equívoco anteriormente estabelecido. O texto anterior incidia sobre a validade de decisões mediante aprovação de quórum mínimo da metade 
mais um de seus representantes. Agora, de modo reparador, ressalva a ocorrência de casos regimentais especiais, os quais exigem maioria qualificada de $2 / 3$ de seus representantes, como, por exemplo, as alterações regimentais internas. A reforma do texto se apresenta conforme segue:

VIII - as decisões do Conselho de Saúde serão adotadas mediante quórum mínimo (metade mais um) dos seus integrantes, ressalvados os casos regimentais nos quais se exija quórum especial, ou maioria qualificada de votos. (BRASIL, 2012, N. P.).

O Reformador fez um importante reparo no item XI, que estabelece a prerrogativa dos Conselhos de Saúde de alçar, quando necessário, auditoria externa e independente sobre as contas e atividades do gestor do SUS. Anteriormente, o texto vinculava essa função aos Conselhos de Saúde somente após ouvir o Ministério Público. Agora, afirmando a sua autonomia, o Conselho de Saúde procede nesse sentido com competência legal, com independência entre as instâncias.

A Quinta Diretriz da Resolução $n^{\circ}$ 453/2012, nos itens XXIII e XXVI, respectivamente citados abaixo, explicita a recomendação aos Conselheiros de Saúde para o acompanhamento dos aspectos éticos envolvidos na incorporação de conhecimentos científicos e tecnológicos.

XXIII - acompanhar o processo de desenvolvimento e incorporação científica e tecnológica, observados os padrões éticos compatíveis com o desenvolvimento sociocultural do País.

XXVII - acompanhar a aplicação das normas sobre ética em pesquisas aprovadas pelo CNS. (BRASIL, 2012, N. P.).

Anteriormente, estabelecia-se a competência dos Conselhos de Saúde em estimular, promover e apoiar estudos e pesquisas sobre assuntos e temas na área de saúde e pertinentes ao desenvolvimento do SUS, mas sem se ater aos conceitos éticos desses meios. A Comissão Nacional de Ética em Pesquisa (Conep), subordinada ao Conselho Nacional de Saúde e ao Ministério da Saúde, mediante a Resolução $n^{0} 466$, de 12 de dezembro de 2012, renovou as diretrizes e normas regulamentadoras sobre as questões de ordem ética nas pesquisas envolvendo seres humanos explicitando a necessidade de acompanhamento dos padrões éticos compatíveis com o desenvolvimento sociocultural do País pelos Conselhos de Saúde. Ao preconizar a necessidade do acompanhamento das normas éticas em pesquisas, o reformador deixou implícita a necessidade de representação dos Conselhos de Saúde como membros natos dos Comitês de Ética em Pesquisa envolvendo seres humanos, o que, pelo contrário, deveria estar explicitamente destacado. Mesmo na presença de pequenos avanços na legislação, há algo a dizer sem som de novidade em prol do aperfeiçoamento dos limites de influência decisória do governo nas coisas do governo. Curiosamente, quem assina a Resolução $n^{\circ}$ 453/2012 são o Presidente do Conselho Nacional de Saúde e o Ministro de Estado de Saúde. Nada de anormal se não se tratasse da mesma pessoa. Essa situação traz à baila ponderar a questão da separação da influência dos poderes e de onde o poder de cada um deve ficar. A ideia central da criação do controle social é expor quando o interesse de um conflitar com o do outro. Assim, cada grupo agirá de acordo com os seus interesses, impedindo os excessos e desmandos do outro. Não faz sentido que o órgão executor e fiscalizador sejam o mesmo. Atribuir a execução e a fiscalização a um mesmo agente seria contrariar os princípios administrativos. Nos âmbitos nacional e estadual, os Conselhos de Saúde, por apresentarem maior autonomia, parecem ter encaminhado esse problema para uma solução. Entretanto, 
muitos municípios ainda atuam à moda antiga, ou seja, o governo municipal detém o amplo comando do Conselho de Saúde. A Resolução reformadora perdeu uma grande oportunidade de pôr fim a isso, e, se não fosse suficiente, ainda reforça o contrário. Para o fechamento deste trabalho, decidiu-se pela transcrição de um relato, ipsis litteris, de um participante da Consulta Pública do Sistema Único de Saúde para a revisão da Resolução no 333/2003 (CNS, 2011), com o objetivo de ilustrar a interferência acima destacada, como barreira enfrentada no cotidiano de muitos Conselhos de Saúde, principalmente por aqueles de menor porte de autonomia.

Os municípios nem sequer oferecem estrutura física e técnica para o funcionamento dos CMS, desta forma, são fragilizados, inoperantes e, com isso, continuam as mazelas na aplicação dos recursos da saúde. O executivo não cumpre a Lei, os conselhos não têm recursos para seu funcionamento. Penso que o Governo Federal deveria estipular percentual para investimento nos conselhos e fiscalizar os municípios quanto à aplicação. No caso da Região Norte, a maioria dos conselhos funcionam dentro das Secretarias de Saúde. Os conselheiros apenas assinam as atas elaboradas pelos secretários de saúde. (CNS, 2011).

\section{Conclusões}

Pelo exposto anteriormente, a Resolução ${ }^{\circ}$ 453, de 2012, reformula e revoga a Resolução $n^{\circ} 333$, de 2003. A reformulação apresenta redação pouco mais extensa, com objetivo de afirmar o que pairava sobre as normas para a instituição, reformulação, reestruturação e o funcionamento dos Conselhos de Saúde. De modo geral, carece de inovação, que, na ordem jurídica, é o elemento preponderante que sustenta as reformulações legais (SOUZA, 2009). Alguns pontos permanecem conflitantes, alguns pontos foram esquecidos de se estabelecer e, no pior dos cenários, há pontos com potencial para causar prejuízos na garantia da proporcionalidade de representação do conjunto da sociedade para o controle social nas políticas públicas de saúde. Por fim, para que o desenvolvimento do exercício desse poder constituinte do controle social do SUS seja efetivamente progressivo na direção da consolidação de uma sociedade mais participativa, faz-se necessário que a sociedade sinta a presença permanente da possibilidade de se envolver nos assuntos públicos da saúde, criticando e propondo alterações regulamentadoras que amparem e garantam esse envolvimento da comunidade. 


\section{Referências}

BRASIL. Constituição da República Federativa do Brasil. Brasília, DF: Centro Gráfico, 1988.

Ministério da Saúde. Conselho Nacional de

Saúde. Para entender o controle social na saúde. Brasília, DF: Ministério da Saúde, 2013.

Ministério da Saúde. Conselho Nacional de Saúde. Resolução $n^{\circ}$ 453, de 10 de maio de 2012. Brasília, DF: Ministério da Saúde, 2012.

CARVALHO, A. L. Os Conselhos de Saúde, Participação Social e Reforma do Estado. Ciência \&t Saúde Coletiva, Rio de Janeiro, v. 3, n. 1, p. 23-25, jun. 1998.

CONSELHO NACIONAL DE SAÚDE (CNS). Consulta Pública do Sistema Único de Saúde: Proposta de Revisão da Resolução ${ }^{\circ}{ }^{3} 333$, de 4 de novembro de 2003. 2003. Disponível em: <http://200.214.130.94/consultapublica/display/dsp_print_completo.php?d=3008>. Acesso em: 24 jan. 2017.

FIRTH, K.; RAYMOND, L. La Organización Social y el Cambio Social. Revista de Ciencias Sociales de la Universidad Iberoamericana, Ciudad de México, v. 5, n. 9, p. 149-183, 2010.

MONELLO, S. As Organizações Religiosas e o Código Civil Brasileiro. 2015. Disponível em: < http://www. advocaciasergiomonello.com.br/SitesTerceiros/ Adv_Sergio_monello2/index.php/component/content/ article/10-noticias-artigos/16-as-organizacoes-religiosas-e-o-codigo-civil-brasileiro>. Acesso em: 20 maio 2017.

PIRES, M. A Religião e o Estado Laico. Disponível em: <https://mauriciopiresadvogado.jusbrasil.com. br/artigos/167709988/a-religiao-e-o-estado-laico>. Acesso em: 24 maio 2017

SIQUEIRA-BATISTA, R.; SCHRAMM, F. R. A eutanásia e os paradoxos da autonomia. Ciência \&t Saúde Coletiva, Rio de Janeiro, v. 13, n. 1, p. 207-221, fev. 2008.

SOUZA, R. C. Análise do Projeto de Lei no 761, de 2007. Consultoria Legislativa da Câmara dos Deputados. Brasília, DF, 2009. Disponível em: < http://www2.camara.leg.br/documentos-e-pesquisa/publicacoes/estnottec/areas-da-conle/tema19/2009_18015.pdf >. Acesso em: 10 fev. 2017.

SPEAR, H. J.; KULBOK, P. Autonomy and adolescence: a concept analysis. Public Health Nursing, Nova Iorque, v. 60 , n. 2 , p. $144-152,2004$.

WEINGARTNER, N. J. Liberdade Religiosa na Constituição: Fundamentalismo, Pluralismo, Crenças, Cultos. Porto Alegre: Livraria do Advogado, 2007.

Recebido para publicação em março de 2017

Versão final em agosto de 2017

Conflito de interesses: inexistente

Suporte financeiro: não houve 